\title{
Observations of planetary transits made in Ireland in the 18th Century and the development of astronomy in Ireland
}

\author{
C. J. Butler
}

\author{
Armagh Observatory, College Hill, Armagh BT61 9DG, Northern Ireland
}

\begin{abstract}
We review the small number of known observations of planetary transits made in Ireland in the 18th century with particular reference to the 1769 observations of Venus by Charles Mason. Though inconclusive, there is evidence to suggest that planetary transits were instrumental in the foundation of at least one of the principal observatories in Ireland. In addition, we note the close personal involvement and the contributions of Nevil Maskelyne, the prime mover of the UK 1769 Transit observations, in the design and equipment of these observatories.
\end{abstract}

\section{Introduction}

It is difficult now to ascertain just how much astronomical activity there was in Ireland in the first half of the 18th century. There was only one university on the island, namely Trinity College or the University of Dublin, founded in 1592 and, whilst undoubtedly some astronomy was taught there by the Professors of Natural Philosophy and Mathematics, there were no public observatories and therefore few opportunities to contribute to the subject on a professional level. The fact that no observations from Ireland of the Transit of Venus in 1761 are listed by Woolf (1959), whereas there were eleven such observations from Great Britain, suggests that astronomical activity in Ireland at this time was at a very low level. In the second half of the 18th century, the situation changed dramatically with the establishment of the Royal Irish Academy, modelled on the Royal Society (McDowell 1985), and two professional observatories, one at Dunsink near Dublin (Wayman 1987) and the other in the ecclesiastical city of Armagh (Bennett 1990). What brought about this change and what part, if any, did planetary transits play?

\section{Charles Mason's observations in $\mathbf{1 7 6 9}$}

The first planetary transit to be observed in Ireland that we have knowledge of was the Transit of Venus in 1769 which was observed by Charles Mason on behalf of the Royal Society. In the autumn of 1768, Mason had returned to Great Britain from the North American Colonies where he had been engaged for the previous four and a half years with his colleague Jeremiah Dixon in laying out the boundary between Pennsylvania and Maryland (the Mason-Dixon Line) and in measuring a meridian arc for the Royal Society. Shortly thereafter, Nevil Maskelyne, Astronomer Royal, asked for volunteers to take part in an expedition to northern Norway to observe the Transit of Venus in June 1769 (see Woolf 1959). These observations were intended to complement those, from the South Seas, by Green and Cook. Mason did not volunteer his services on this occasion, possibly because of the rather off-hand treatment he had received from the Royal Society at the beginning of a previous engagement to observe the transit of 1761 when he had to return to port after an attack from a French frigate. Maskelyne, aware of Mason's exceptional ability as a surveyor and astronomer, was anxious not to lose his expertise in 
this important project and suggested instead that he observe the transit from northwest Ireland. As Maskelyne emphasised in his outline of procedures for the 1769 transit in the Nautical Almanac, observations were required from a variety of locations, both to improve the accuracy of the determination of the Astronomical Unit and to overcome the vagaries of the weather. However, there was another reason for Maskelyne's choice of northwest Ireland, namely, that here at the time of first contact, Venus would have an altitude nearly twice it would have at Greenwich. Hornsby (1765) had warned, and Maskelyne was well aware, that at an altitude of $6^{\circ}$ at Greenwich the times of first and second contact would be difficult to determine from a site so close to sea level. At $12^{\circ}$ altitude, Mason would have a much better chance of making definitive observations from the northwest of Ireland.

Mason agreed to go and, by late January 1769, his terms had been agreed with the Council of the Royal Society, at 100 guineas for his maintenance and gratuity and 20 guineas for travel (Maskelyne 1769a). By the beginning of March, Mason was already on his way, first by road to Holyhead and then by the appropriately named vessel 'Venus' to Dublin (Mason 1770a). He set sail on 10 March but a storm during the night and following morning prevented the ship entering Dublin Bay and they were forced to round Howth Head and land about 20 miles north of Dublin. With customs formalities to attend to as well as the ongoing journey overland, he arrived in Strabane, County Tyrone on 19 March, nearly three weeks after leaving London. He immediately set about finding a suitable spot for his observatory.

Maskelyne had given clear instructions as to the type of site he was to select together with what soon turned out to be an optimistic schedule for the project:

You are expected by the Council of the Royal Society to proceed with the utmost dispatch to Londonderry or to any place towards the North West coast of Ireland lying between Londonderry and Galway Bay, which you shall find to be the most proper for the purpose of making astronomical observations. You will therefore chose a place free from fogs arising from bogs or lakes or very high land but a moderate elevation will be very advantageous. You will endeavour to settle at such a place by the 8th of March next, in order to be ready to observe the eclipses of Jupiter's satellites for two months before Jupiter's opposition to the Sun, and you will continue your observations here for the space of four months.

By the 24 March, Mason had settled on the townland of Cavant, near Lifford in County Donegal, within sight of the city of Londonderry. The next week was taken up with transporting his equipment to Cavan and setting up his observatory (with a movable top). The instruments he had been provided with, in common with the other expeditions of the Royal Society, included a 12-inch quadrant by Bird, a 2-foot Gregorian telescope (by Short or Bird) and a clock by Shelton (Howse 1989). On the journey to Ireland, the pendulum spring of his clock by Shelton had been broken in two places. This was replaced, but the readjustment meant that he was not able to make the gravity comparison with Greenwich at that time, as originally intended.

Observations started on 3 April 1769 and, with two months to go before the Transit, he should have had adequate time for many of the important preparatory observations. He proceeded to make observations of stars at equal altitudes for setting his clock and zenith distances for latitude. Though he made observations on 13 days in the remainder of April, bad weather set in and he was able to observe on only 9 days in May. However,

$\dagger$ The townland of Cavan should not be confused with the county town of Cavan some 60 miles to the south. 


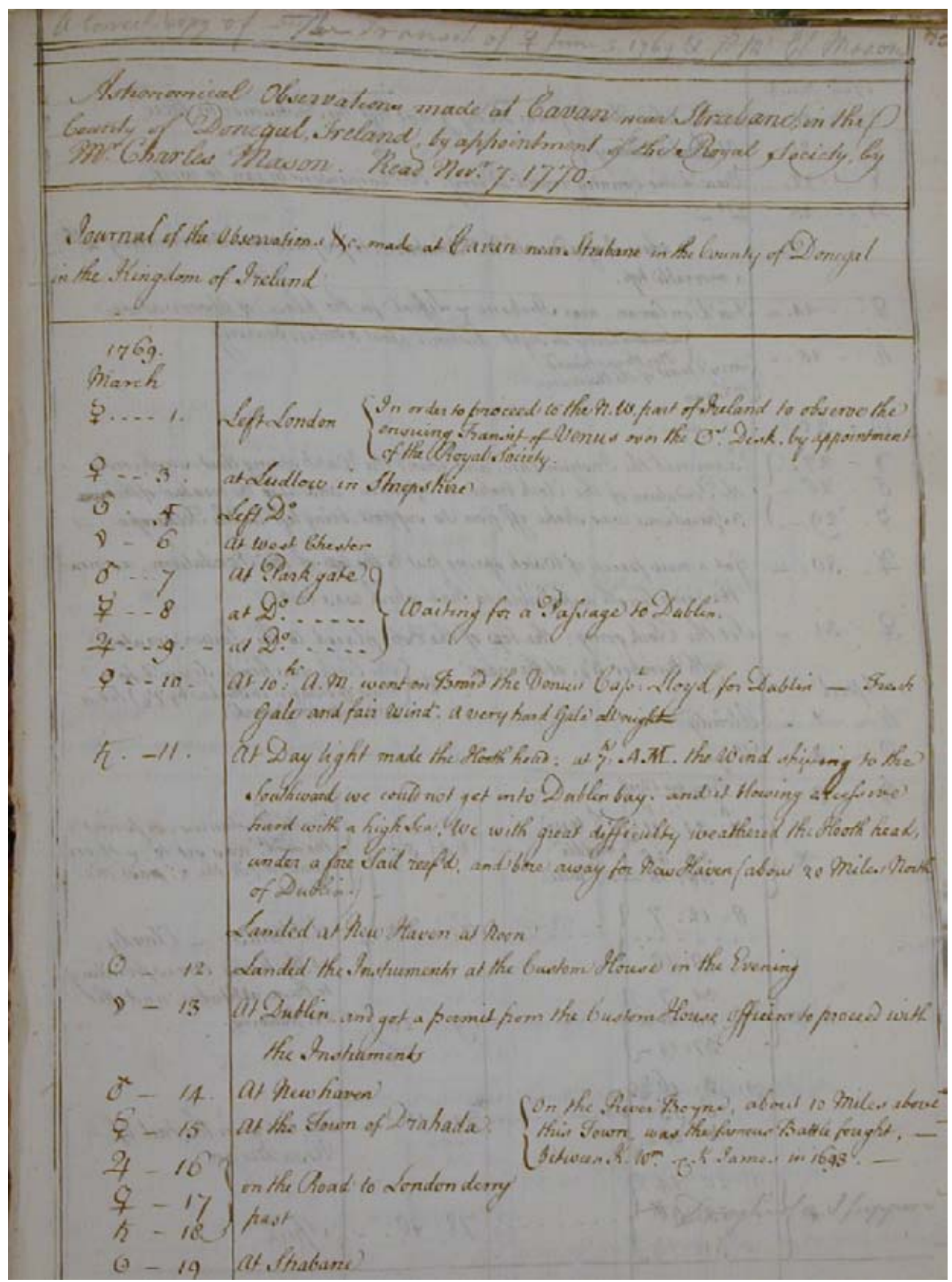

Figure 1. The first page of Charles Mason's Journal of Observations from Cavan, County Donegal. (courtesy of the Royal Astronomical Society)

on the crucial day of the Transit, it was clear enough for him to time the outer and inner contacts at ingress. In addition, like many other observers, he noted the black drop effect.

At internal contact, the air was much changed and the limb of Venus seemed to adhere to the Sun's limb by a protuberance that appeared like a dark shade: which seemed to prevent seeing the thread of light for about $40^{s}$ longer than expected... 


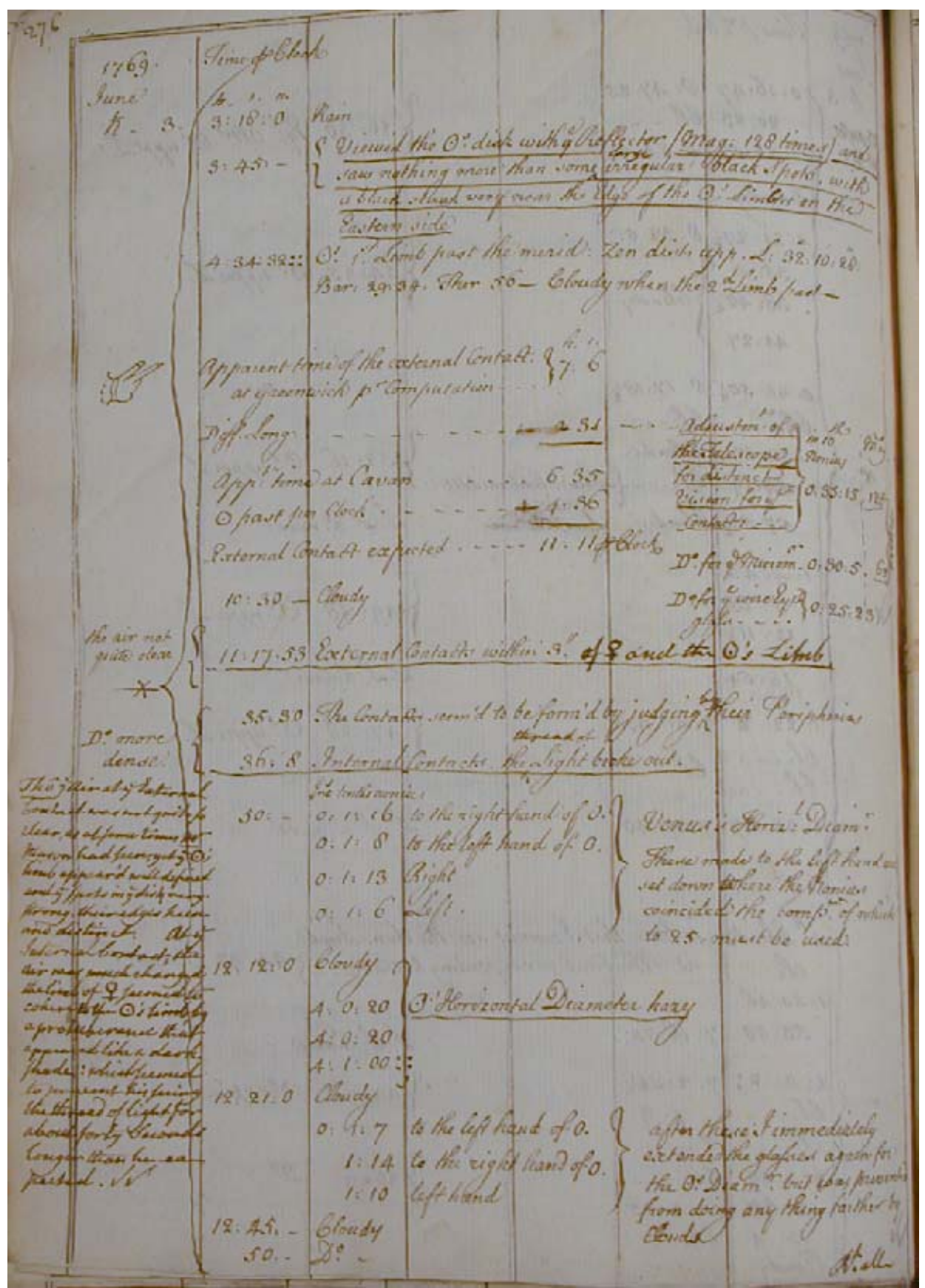

Figure 2. The page from Mason's journal showing his observations of the Transit of Venus. (courtesy of the Royal Astronomical Society)

Mason also remarked on a thin halo around Venus when seen against the Solar disk: ...there appeared a faint light shade (having a gentle fluctuating motion) round its periphery, and widest on that part farthest on the sun's disk ...very regular and well defined ...the whole shade was apparently of equal brightness... 


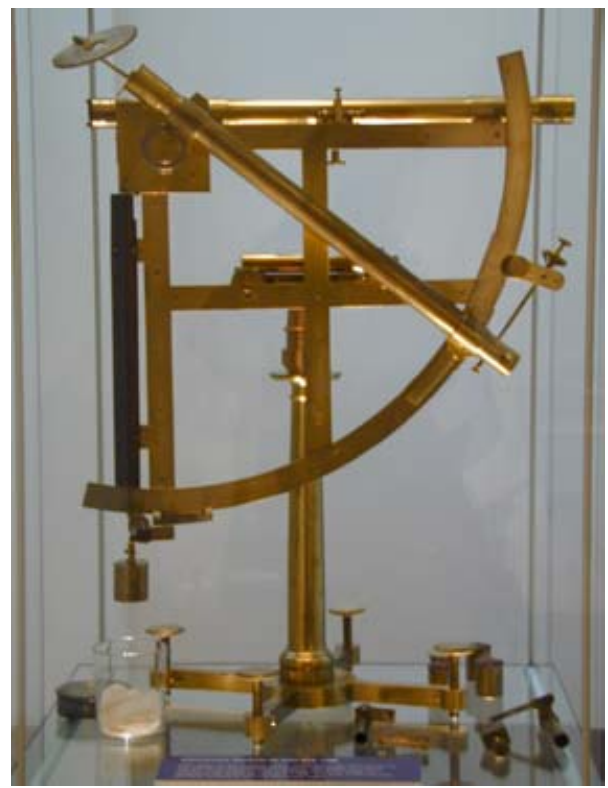

Figure 3. A Quadrant of 12 inches radius by John Bird, made in 1768 for the Royal Society's Transit of Venus Observations the following year. (courtesy of the Royal Society)

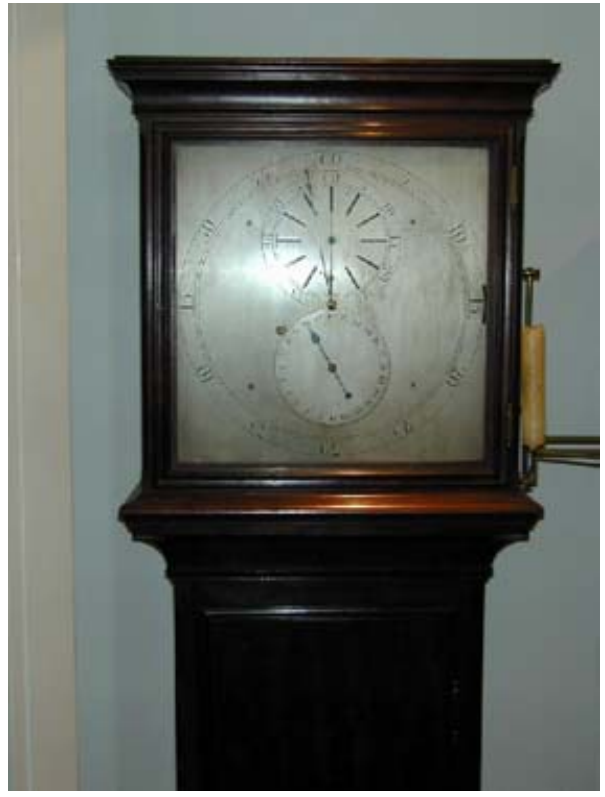

Figure 4. An Astronomical Regulator by Shelton from the Kew Observatory, made for the Transit of Venus, 1769. (Armagh Observatory)

Though conditions were far from perfect, nonetheless, Mason had observed both contacts at ingress and when Maskelyne received word from him on 21 June, he was evidently very pleased. The only point of regret was that clouds and rain had prevented Mason from seeing the whole of the following solar eclipse, which, if he had observed it in its entirety, would have gone a long way to fixing his longitude. Though Mason had only been 


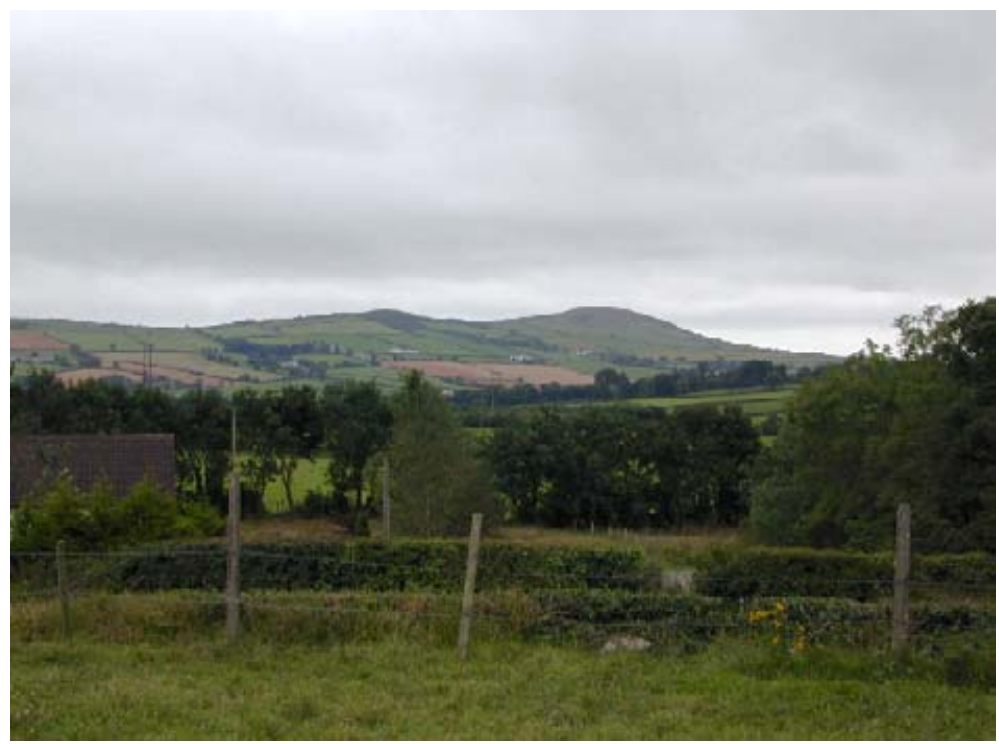

Figure 5. The view from the townland of Cavan, Co Donegal, towards the southern horizon. (photo by the author)

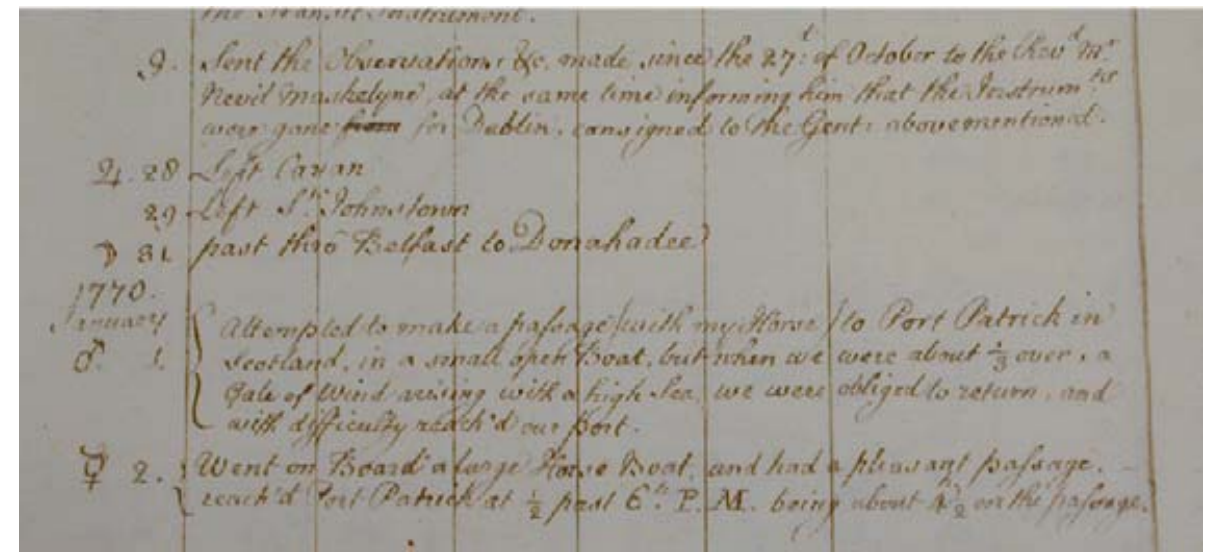

Figure 6. The entry in Mason's diary concerning his departure. (courtesy of the Royal Astronomical Society)

contracted for four months, Maskelyne pleaded with him to stay on until his longitude was settled. He proposed that Mason observe fainter stars close to the Moon that could subsequently be observed at Greenwich. Maskelyne (1769b) wrote

You have been very diligent and taken a great deal of pains, a great part of which has been disappointed by cloudy weather, but go on and don't despair, for without more, what you have already done will go near being lost.

Mason followed Maskelyne's suggestions and made additional observations of the occultation of stars by the Moon. But, time and again, when Mason tried to observe an occultation suggested by Maskelyne, he was clouded out, and when Mason succeeded, Maskelyne failed. Computed lunar positions, it seems, were insufficiently accurate at this time, and only observations on the same night at both Cavan and Greenwich would suffice for an accurate longitude. 
At that time, Maskelyne knew nothing about how the observers sent to the North Cape and North America had fared and it would be two years before he heard details of the observations by Green and Cook in Tahiti. He was clearly delighted with Mason's observations but he emphasised that without an accurate longitude Mason's observations of ingress could not be combined with observations of egress by other observers in the northern hemisphere. The importance Maskelyne attached to Mason's observations intensified as he later learned of the failure through bad weather of Dixon and Bayley's observations from the North Cape. Meanwhile, to improve the accuracy of Mason's determination of longitude, Maskelyne had sent him from Greenwich a four-foot transit instrument. This instrument arrived at Cavan on 21 September and by 3 October Mason had it set up with meridian marks defined the following day. With an improvement in the weather, Mason made transit observations on 34 nights in October and November. In the end he had five successful observations of occultations in Cavan and thirteen observations of lunar transits for which Maskelyne had corresponding observations from Greenwich. With his longitude now defined he finally packed the instruments on 27/28 November and dispatched them to Greenwich via Dublin on 7 December.

Just how accurate Mason's surveying work was is illustrated by a table at the end of his journal containing 50 individual determinations of the latitude of his observatory at Cavan. The mean latitude from Mason's observations is $54^{\circ} 51^{\prime} 44^{\prime \prime} 8$ with a standard error of the mean of only 1."8, equivalent to 55 metres on the Earth's surface. The RMS deviation of a single determination of latitude was $13^{\prime \prime}$, equivalent to $400 \mathrm{~m}$. When we consider that these deviations include errors in the tabulated stellar positions and reading error as well as errors in the division of the scale, we can appreciate not only Mason's expertise, but also the ingenuity of his friend, John Bird, who had manufactured his onefoot radius quadrant. Its probable that Mason's observations from Donegal represent one of the most precise bodies of astronomical data to have been collected in Ireland at that time.

With nearly nine months spent in Ireland on a project that he had expected to take, and was only contracted for, four months, Mason seemed to be in no hurry to depart as he didn't actually leave Cavan till 28 December. Arriving in Donaghadee on the County Down coast on 31 December he first attempted to cross the Irish Sea (with his horse) in a small open boat. However, bad weather as always kept him company, and about one third of the way over he was forced to return to the Irish coast where he was fortunate to regain land. The following day, he records that he made the journey in comfort in a house boat in four and a half hours. From the Scottish coast he continued his journey by road, finally reaching London at six o'clock in the evening of 13th January 1770.

Maskelyne (1770) gave an extended report to the Council of the Royal Society outlining the many observations made in Donegal by Charles Mason and their ultimate success in establishing the location of his observatory, which he wrote is now settled with greater exactness than any other place where observations of the transit have been made. In spite of the inclement weather and the many problems Mason had faced, he had eventually achieved all he had set out to do. It is worthwhile to ponder on why Mason had succeeded where some others had failed. The surviving letters from Maskelyne to Mason give the clue and demonstrate the importance to success of the iteration between the two correspondents. When Mason had so many difficulties determining his longitude, it was Maskelyne's encouragement, advice and help with additional observations from Greenwich that saved the day, for, in spite of the detailed instructions Maskelyne gave to each of his observers in advance, changes in the type of observations required, extra time and even additional equipment were necessary to complete the project. For Dixon and Bayley at the North Cape, no such iteration through correspondence with Maskelyne was 
possible, whereas with Mason, together with a bit of luck on the Transit day, it ensured eventual success.

\section{Maskelyne, Hamilton and Ussher and the foundation of observatories in Ireland}

Mason's observations were published in full in the Transactions of the Royal Society (Mason 1770b). Though this seems to have had little or no impact in Ireland, there is no doubt that the whole Transit of Venus exercise and Maskelyne's leading role in it, had conspicuously raised his profile, both amongst the fellowship of the Royal Society and beyond. With the publicity that surrounded Captain Cook's return and the major contributions his voyage had made to astronomy, botany, anthropology and navigation, Maskelyne was now a major player in British science. So when moves were first made in Ireland in the second half of the 18th century to promote astronomy, it was natural that Maskelyne should be consulted.

One of his earliest involvements was to host and tutor two Irish astronomers, namely Henry Ussher (1740-1790) and James Hamilton (1748-1815). Both were graduates of Trinity College, now in holy orders, and would in time become the first directors of the two public observatories at Dunsink and Armagh.

Hamilton had visited Maskelyne at Greenwich in the early 1780s where he had evidently developed his interest in the transits of the inner planets and their use in determining the dimensions of the solar system. He later wrote a comprehensive account listing values for the solar parallax from observations of the Transit of Venus made in 1761 and 1769 (Hamilton 1810). These he then combined with values for the Earth's radius from measurements of various meridian arcs to calculate the size of the astronomical unit. The value he derived for this was 95 million miles.

On 12 November 1782 Hamilton observed a Transit of Mercury from his house near Cookstown, County Tyrone. He wrote to Maskelyne with details of his work and Maskelyne promptly replied, congratulating him on his successful observations which, because of more favourable atmospheric conditions, were superior to those made at Greenwich. Maskelyne requested further details and subsequently decided to convey Hamilton's observations to the Royal Society for publication (Hamilton 1783). It was reported many years later by a clergyman in Armagh (Elliott 1882) that Richard Robinson, Archbishop of Armagh, was so impressed with Hamilton's work, or at least Maskelyne's recognition of it, that he decided to include an observatory in his plans for rebuilding the City of Armagh and to make Hamilton its first director. Hamilton, appointed in 1790 with a certificate of competence from the Astronomer Royal, lost no time in asking for Maskelyne's assistance in selecting instruments and clocks for the new observatory. Once again, Maskelyne, mindful of his colleague's needs, provided expert advice in abundance and took it upon himself to test the accuracy of several clocks at Greenwich before recommending them to Hamilton and the Archbishop (see Maskelyne 1790).

Likewise, in 1783, after Henry Ussher was appointed the first Andrews Professor of Astronomy in the University of Dublin, he went straight to London to order instruments from Ramsden and to meet with Maskelyne. Though Ussher had few scientific papers to his name and none, at that time, on astronomy, he was evidently well aware of the basic requirements of an observatory. There seems little doubt that he learned many of these from Maskelyne on his visits to Greenwich (Wayman 1987). In the event, Ussher, together with his architect, the little known Graham Moyers, created a landmark building in Dunsink Observatory. Indeed, Donnelly (1973) in her classic book on observatory architecture, considered it to be the prototype for later European and American observatories. 


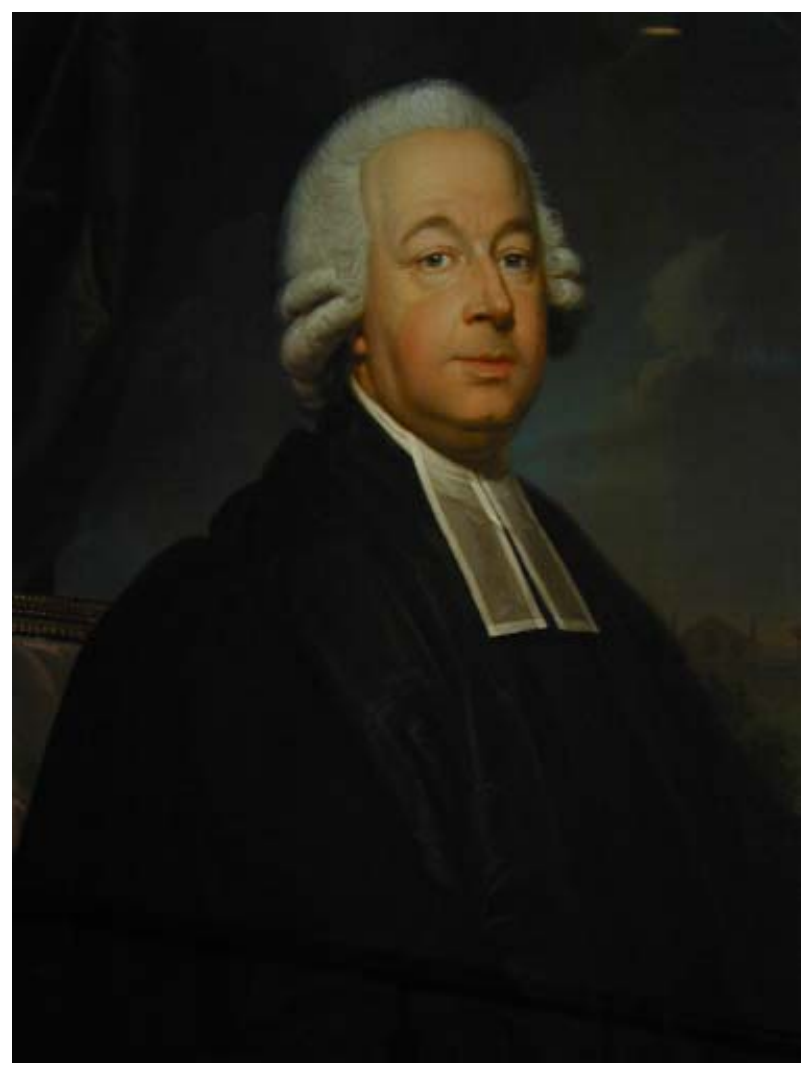

Figure 7. Nevil Maskelyne (1732-1811) the fifth Astronomer Royal, in 1785, by L.F.G. Van de Puyl (Courtesy of the Royal Society, photo by the author)

Though there were evident influences from Scandinavia, from Greenwich, and the Radcliffe Observatory in Oxford, it was Dunsink that clearly placed scientific practicality first and aesthetics second. Ussher wrote an excellent account of why Dunsink Observatory was built as it was, with great attention to the location of the Observatory and its observing rooms, the provision of stone pillar supports for instruments with foundations independent of the buildings in which they were housed, and the need for ventilation to reduce seeing problems close to and within the building (Ussher 1787). Though Ussher and Moyers were clearly extremely capable and practical men who together created a masterpiece, in all the above respects we see the guiding hand of the experienced astronomer, Nevil Maskelyne.

\section{Astronomy in Ireland in the 19th Century and later}

With two public observatories now established in Ireland, the way was open for promising young mathematicians to become engaged in astronomy. Edward Cooper of Markree, County Sligo and the third Earl of Rosse in Birr, County Offaly, became attracted to the subject and the stage was set for a rapid advancement of practical astronomy in Ireland with, in 1834, the largest refracting telescope in the world at Markree, and with the largest reflector in the world at Birr from 1845 till the end of the century. This was Irish astronomy's golden age, culminating with the discovery of spiral structure in galaxies, 


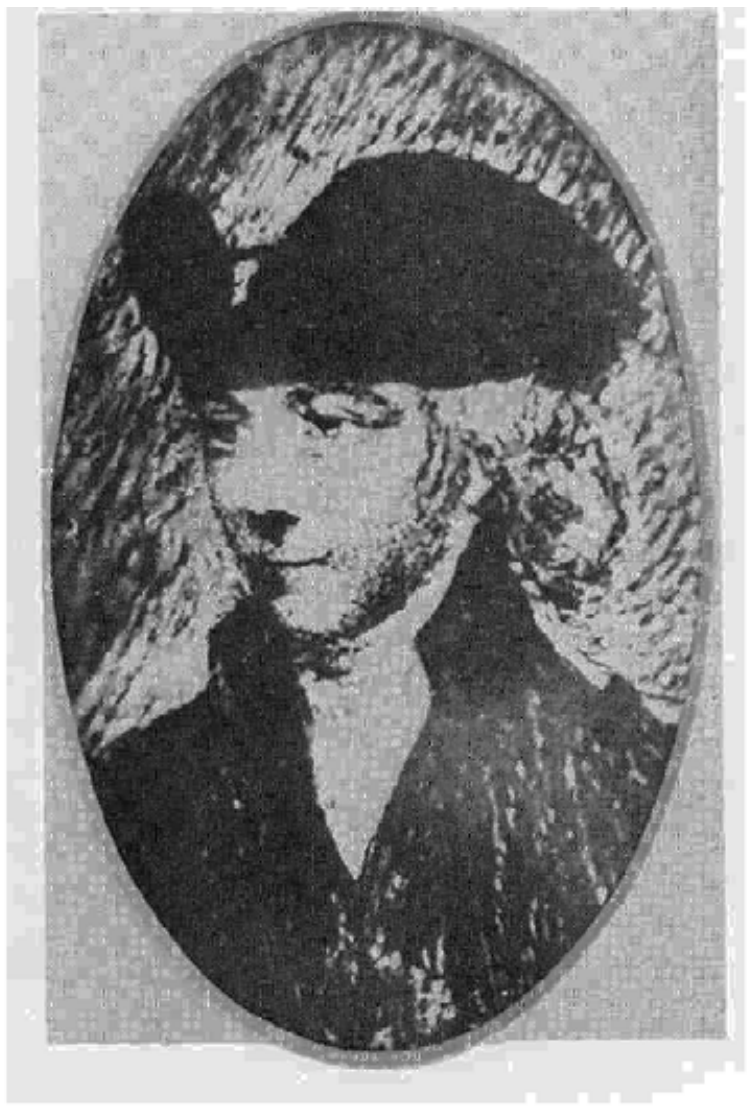

Figure 8. A drawing of Henry Ussher (1740-1790) first Andrews Professor of Astronomy at Trinity College Dublin. (courtesy of Dunsink Observatory)

the compilation of the NGC Catalogue and the great advances made by the Grubb family in telescope manufacture and design.

The increase in astronomical activity in Ireland during the 19th century can be seen in the list of observatories that contributed observations of the Transit of Venus in 1882: Dunsink, Armagh, University College, Cork, Markree and Daramona. Clouds, however, were by this time already on the horizon as reforms in the land tenure system which started in the late 19th century led to the break up of the great landed estates which had financed most of the observatories. With their estates gone, the landed gentry were no longer in a position to support such an esoteric pursuit as astronomy and within a few decades Ireland had lost almost all of the impetus it had built up in the physical sciences in the previous century. It was not till the middle of the 20th century that Hermann Brück and Eric Lindsay, with help from the then Taoiseach and former mathematics teacher, Eamon De Valera, began a new renaissance in astronomy in Ireland.

\section{Acknowledgements}

Armagh Observatory is grant-aided by the Department of Culture, Arts and Leisure for Northern Ireland. The author would like to thank: Dr Peter Hingley of the Royal Astronomical Society, Dr Adam Perkins of Cambridge University Library and the staff of the Royal Society for providing access to archival material. 


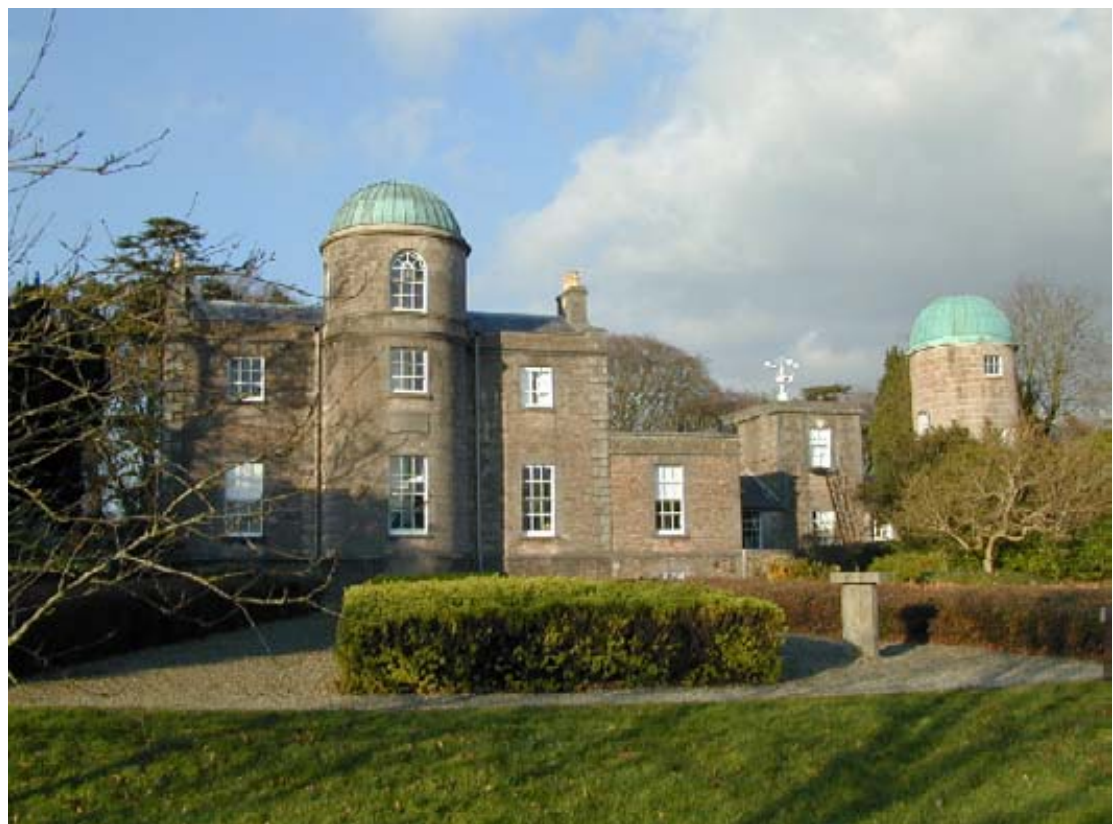

Figure 9. Armagh Observatory, founded in 1790 by Archbishop Richard Robinson. (photo by the author)

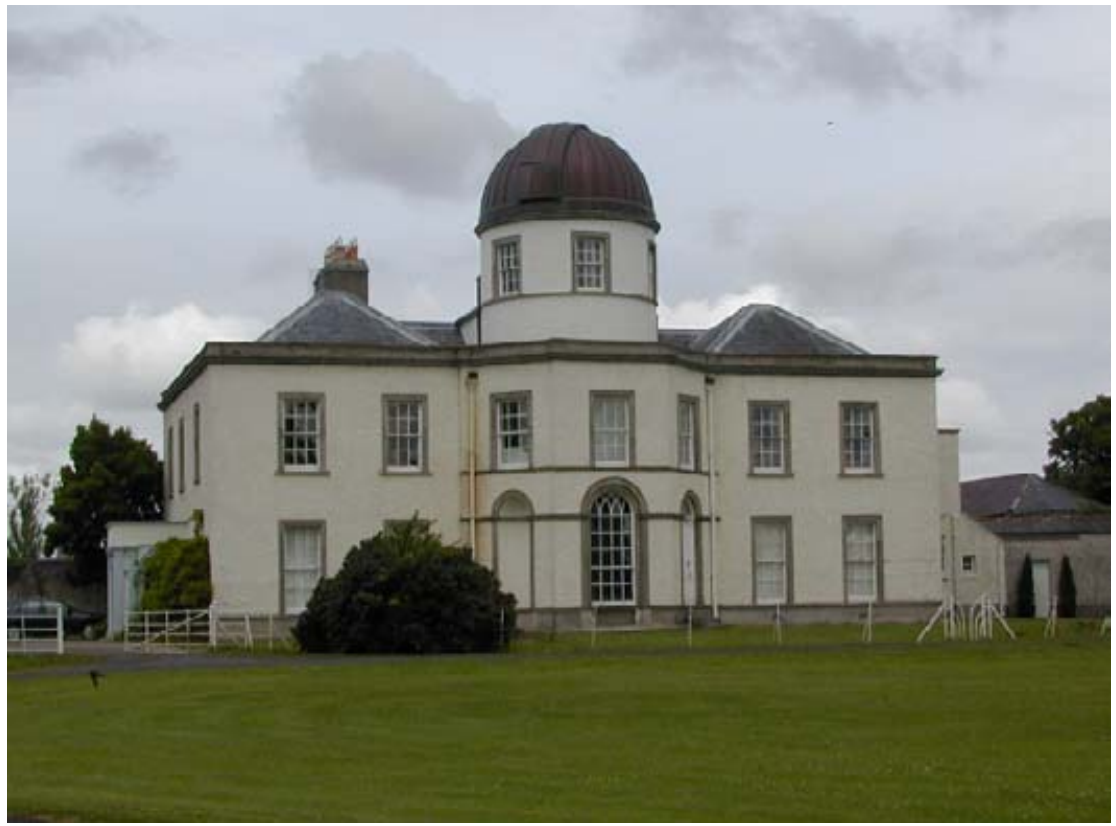

Figure 10. Dunsink Observatory, founded in 1785 by Trinity College, now a part of the Dublin Institute for Advanced Studies. (photo by the author)

\section{References}

Bennett, J.A. 1990 Church, State and Astronomy in Ireland - 200 years of Armagh Observatory, Armagh Observatory

Donnelly, M.C. 1973 A Short History of Observatories, University of Oregon Books 
Elliott, Rvd. J. 1882. Newspaper report of discussion following a lecture by J.L.E. Dreyer, 18 December 1882 on the Transit of Venus, Minutes Book for General Meetings of the Armagh Natural History and Philosophical Society, 1869-1892, Armagh County Museum.

Hamilton, J.A. 1783. Extract of a letter from the Rev. James Augustus Hamilton, M.A. to the Rev. Nevil Maskelyne, D.D., F.R.S. giving an account of his observations of the Transit of Mercury over the Sun, of Nov. 12, 1782, observed at Cookstown, near Dungannon, in Ireland, Phil. Trans. Royal Society, 73, 453-455.

Hamilton, J.A. 1810 "An Essay on the Present State of Astronomical Certainty, with regard to the quantity of the Earth's magnitude, the distance of that planet from the Sun, and the absolute limit of the smallest possible interval from the Sun to any one of the fixed stars," Trans. Royal Irish Academy, 11, 13-24.

Hornsby, T 1765 "On the Transit of Venus in 1769," Phil. Trans. Roy. Soc., 55, 265-274.

Howse, D. 1989 "Nevil Maskelyne - the Seaman's Astronomer," Cambridge

Maskelyne, N. 1769a Letter to Charles Mason, dated 31 Jan. 1769, Archives of the Royal Greenwich Observatory, Cambridge University Library, Ref. 184.3

Maskelyne, N. 1769b Letter to Charles Mason, dated 24 June 1769, ibid, Ref. 184.9

Maskelyne, N. 1770 Manuscript; Council Minutes of the Royal Society, Vol 6, 67-70.

Maskelyne, N. 1790 Letter to J.A. Hamilton, dated 16 Feb. 1790, Armagh Observatory Archives M51.4, Butler, C.J. and Hoskin, M.A. 1987, J. Hist. Astron. 18, 295-307.

Mason, C. 1770a Astronomical Observations made at Cavan near Strabane in the County of Donegal, Ireland by appointment of the Royal Society, Manuscript; Royal Astronomical Society, ADD MS 8.

Mason, C. 1770b On the Transit of Venus, and other Astronomical Observations made at Cavan, near Strabane, in the County of Donegal, Ireland, by appointment of the Royal Society, Phil. Trans. Royal Society, 60, 80 \& 60, 454-496.

McDowell, R.B. 1985 The Royal Irish Academy - a bicentennial history 1785-1985, T. O'Raifeartaigh (ed), Royal Irish Academy, Dublin. 1-92.

Ussher, H. 1787 "Account of the Observatory belonging to Trinity College, Dublin", Trans. Royal Irish Academy, 1, 3-21.

Wayman, P.A. 1987 Dunsink Observatory, 1785-1985, Royal Dublin Society.

Woolf, H. 1959 The Transits of Venus - a study of Eighteenth-Century Science, Princeton.

\section{Discussion}

Ed Budding: John, what about the 13-inch Markree Refractor? Do you know what happened to it?

John Butler: The lens still survived. The telescope was taken to Hong Kong and reerected there by the Jesuits, but it was bombed in the air raids of the Second World War; I'm not sure who did the bombing, but anyway the telescope was destroyed. The lens survived and was taken to the Philippines, where it still is. It's in Manila, I think.

ED BudDing: The observatory building is still there, isn't it? The base of the building is still in the grounds.

JoHn BuTLER: That photograph actually was taken about ten years ago, so that's all that is really left, just a few walls. The Castle is still there, but not the observatory.

MARY BRÜCK: I can add to that: last week they were selling the gate lodge of Markree.

John ButLER: The observatory was sold as well.

MARY BRÜCK: They are trying to get people to buy this and spend a million Pounds, or so, on account of it's astronomical associations. 
Suzanne Debarbat: Do you know how many small quadrants made by Bird are actually still surviving? Because you have shown one, so there could be very many.

John Butler: The only one I know of is the one at the Royal Society, which is the one I showed a picture of. That's on display at the Royal Society at the moment actually.

Wayne Orchiston: Given all the problems that Mason had on trying to establish his longitude, why didn't he observe Jovian satellites on the odd clear nights? They are frequent; they are listed in the nautical almanac - instead of waiting for lunar occultations.

John Butler: He did observe some, but I think that Jupiter was in opposition, or going into opposition shortly after June, but he got one observation, I think.

MARY BRÜCK: Thank you, John. It's heartening to find that the observations of the Transit of Venus, even if they brought no astronomical results, did result in observatories being built in Ireland. Now there is such a great interest in this country [UK] in the Transit of Venus yesterday. Let's hope it has the same result this time.

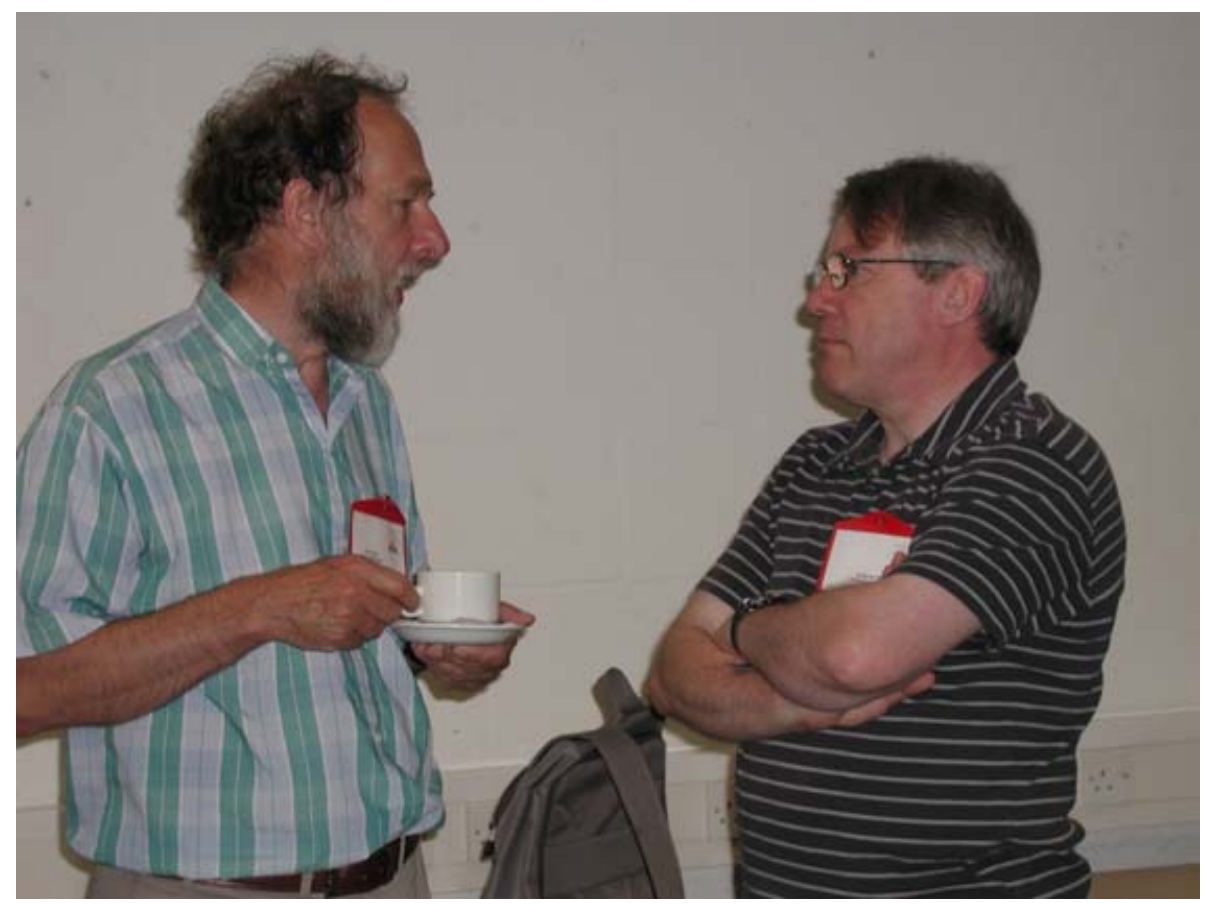

John Butler and Simon Mitton 